\title{
Elementos ontológicos, epistemológicos y metodológicos para la construcción de un marco teórico de estudio de los activos intangibles*
}

\author{
Ontological, Epistemological and Methodological Elements for the Construction of a Theoretical Framework for the \\ Study of Intangible Assets \\ Elementos ontológicos, epistemológicos e metodológicos para a construção de um quadro teórico de estudo dos \\ ativos intangíveis
}

Juan Pablo Hincapié M. ${ }^{\text {a }}$

DOI: https://doi.org/10.11144/Javeriana.cc18-45.eoem

Universidad del Valle, Colombia

juan.pablo.hincapie@correounivalle.edu.co

ORCID: http://orcid.org/0000-0003-3776-7670

Fecha de recepción: 14 Noviembre 2016

Fecha de aprobación: 13 Marzo 2017

\section{Resumen:}

Hablar en contabilidad de revelación de información implica, inexpugnablemente, referirnos al menos a la concatenación de los procesos de representación (semióticos), medición, valoración y representación (contable). El objetivo de este documento es exponer en clave crítica una serie de reflexiones que subyacen en los discursos contables respecto de la representación y de la crisis de la representación de lo intangible. Se espera que las reflexiones aquí esbozadas abonen elementos ontológicos, epistemológicos y metodológicos idóneos para la construcción de un marco teórico para los activos intangibles que sugerentemente apuntan a elaborar Kaufmann y Schneider (2004).

Códigos JEL: M40, M41, M49.

Palabras clave: Representación, medición, valoración, revelación, discurso contable, activos intangibles.

\begin{abstract}
:
Speaking of information disclosure in accounting invariably implies referring, at least, to the concatenation of representation processes (semiotic), measurement, valuation, and representation (accounting). The purpose of this document is to present in a critical way a series of reflections that underlie accounting discourses regarding representation and the crisis of the representation of the intangible. It is expected that the reflections outlined here will provide ontological, epistemological, and methodological elements suitable for the construction of a theoretical framework for the intangible assets tentatively suggested by Kaufmann and Schneider (2004).
\end{abstract}

Keywords: Representation, measurement, assessment, revelation, accounting discourse, intangible assets.

\section{Resumo:}

Falar em contabilidade de revelação de informação implica, inexpugnavelmente, nos referir ao menos à concatenação dos processos de representação (semióticos), aferição, valoração e representação (contábil). O objetivo deste documento é expor, em chave crítica, uma série de reflexões subjacentes nos discursos contábeis no que diz respeito da representação e a crise da representação do intangível. Espera-se que as reflexões aqui esboçadas adiram elementos ontológicos, epistemológicos e metodológicos idôneos para a construção de um quadro teórico para os ativos intangíveis que de jeito sugeridor apontam a elaborar Kaufmann e Schneider (2004).

Palavras-chave: Representação, aferição, valoração, revelação, discurso contábil, ativos intangíveis.

\section{Introducción}

Research should concentrate much more on theoretical approaches to explain the functions of intangibles. Different theories could be investigated.

Notas de autor 
[...] Can researchers studying intangibles in general offer suggestions that can be transferred into business life, or must one focus on a specific kind of intangibles in order to offer concrete descriptions and suggestions? This then also raises the question of how to categorize intangibles. A possible solution to this problem could be to create a theoretical framework for all intangibles that can be adapted to special sub-cases as the need arises.

Kaufmann \& Schneider (2004, p. 384)

Históricamente, por medio de sus esquemas teóricos y metodológicos, a la contabilidad le ha correspondido la función de recopilar, clasificar, analizar y elaborar información que dé cuenta de los hechos contables que acontecen en los segmentos de la realidad económica, financiera, legal, social y ambiental, tanto en el campo de las organizaciones empresariales como en el contexto de las naciones. Hablar, entonces, de discurso contable ${ }^{1}$ y de revelación de información en contabilidad, remite a un amplio panorama de problematización que recae sobre las nociones ontológicas de la realidad, el debate de su estatuto epistemológico, la polisemia de sus discursos y, por supuesto, los procesos de medición, valoración y representación que atañen a este campo del conocimiento.

Algunas preguntas que emergen a la superficie de este panorama de problematización cuestionan la idea de realidad que discurre sobre las perspectivas naturalistas y construccionistas. Un puñado de ellas se remiten al ambiguo trasegar epistemológico en el que transita o se pretende anclar a la contabilidad, concibiéndola como arte, técnica, tecnología, disciplina y/o ciencia. Otras cuestionan la forma o la capacidad performatival deformada en que la contabilidad construye y oculta, o bien, revela sus discursos, mientras que otras pocas debaten sobre la frontera que se establece entre lo ortodoxo y lo heterodoxo que detenta o desvía su discurso y accionar social. En tanto, otras más relativizan los elementos, esquemas y procedimientos utilizados para establecer las magnitudes y objetos sobre los que recae el quehacer contable y su proceso de revelación.

La anterior situación problémica cobra mayor trascendencia en lo concerniente a los activos intangibles (en adelante AI) debido al inadecuado tratamiento que los organismos reguladores y profesionales han normalizado a este tipo de recursos inmateriales que, tanto a nivel nacional como internacional, vislumbran para lo inmaterial procedimientos equivalentes a los de los activos fijos o materiales. En otras palabras, se privilegia la escogencia de ciertos criterios y técnicas de medición, representación, valoración y revelación, confinando con ello a un segundo plano la problematización ontológica, epistemológica y metodológica de los cuatro procesos ya contemplados y cuyos nombres cabe recordar: la medición, la representación, la valoración y la revelación. Lo mismo ha sucedido con la capacidad y potencialidad de revelación/ocultación que subyace bajo los discursos de los intangibles en la contabilidad financiera.

En este orden de ideas, se justifica la elaboración de unas breves aproximaciones reflexivas que intentan auscultar a lo largo del proceso de revelación en la contabilidad y en concreto de los AI, las grietas que subsisten en su andamiaje metodológico, ontológico y epistemológico, al igual que en su esquema conceptual, en una clave crítica. Lo anterior tiene el objetivo de proveer algunas luces que permitan orientar la construcción de un marco de estudio sólido y fundamentado sobre lo intangible, al menos en lo que concierne a la contabilidad financiera.

El documento se encuentra dividido en cuatro partes y se apoya, para su construcción y exposición, en las inferencias deductivas y en el análisis de contenido, que encuentran su fundamento en la revisión bibliográfica aquí indicada. Así las cosas, en la primera parte se revisan algunos asuntos vinculados con el andamiaje ontológico, epistemológico y metodológico que atañe a la contabilidad. En la segunda parte se realiza una exploración del proceso de revelación en lo que compete a la contabilidad; estudio que implica, a su vez, una revisión de los procesos de construcción categorial (primer estadio de la representación), y avanzar por las nociones de medición y valoración contable, hasta llegar al segundo estadio de la representación de la contabilidad, que se refiere a la partida doble (en adelante PD).

En la tercera parte se identifican algunas nociones y características del estudio de los AI para exponer, en la siguiente parte, una serie de críticas subyacentes en algunos de los discursos que se tejen en la contabilidad de manera general y sobre ese tipo de activos de manera particular; discursos que recaen así sobre los procesos de 
la categorización-conceptualización, la medición-valoración y la representación-revelación. El texto finaliza con algunas conclusiones preliminares que invitan a ulteriores exploraciones.

\section{Andamiaje onto-epistemológico y metodológico aplicado a la contabilidad y a los activos intangibles}

\subsection{Encuadre ontológico}

Responder las preguntas ¿qué es la realidad? y ¿qué es la representación?, es un asunto eminentemente ontológico. En ese sentido, existen al menos dos corrientes de interpretación de la realidad: una de tipo positivista, natural, materialista u objetivista, y otra de tipo subjetiva, social, constructivista o intersubjetivista. Respecto de la primer corriente de interpretación de la realidad, los profesores argentinos Walter Carrizo y Silvia León (2011) plantean que según esta postura "existe un mundo real y objetivo, independiente de los seres humanos, con una naturaleza o entidad propia, susceptible de ser cognoscible” (p. 21). En tanto, para Marco Antonio Machado (2011), la realidad corresponde desde una perspectiva objetivista a la sustitución del objeto ausente, es decir: a la acción de "darle presencia y confirmar la ausencia" del objeto (p. 156).

En cuanto a la segunda corriente de interpretación de la realidad, Carrizo y León (2011) señalan que esta es creada y recreada constante y subjetivamente, por lo que es preciso referirse a una realidad de tipo social. En esa dirección, los autores esgrimen que "la realidad social se construye gracias a la intervención del lenguaje y la interpretación de lo medido o descrito” (p. 21). Machado (2011) establece un matiz en cuanto para él la realidad es una "construcción fruto de las interacciones sociales" en la que no hay cabida para el objeto explícito de representación, sino que tal objeto se inscribe en el mundo de lo social en la "medida en que sea construido por los seres humanos en sus interacciones a través del lenguaje” (p. 156).

De acuerdo con Carrizo y León (2011), puede enunciarse un tercer tipo de corriente interpretativa de la realidad, la cual es planteada según los preceptos de Richard Mattessich, quien considera que la realidad está construida por diferentes niveles o "capas de cebolla" dependientes de e incluidas una en la otra. Los niveles de la realidad planteados por este investigador de origen italiano se circunscriben a cuatro capas: (1) la realidad físico-química, (2) la realidad biológica, (3) la realidad mental y (4) la realidad social. Según esta postura, "la contabilidad trabaja sobre una realidad social" orientada hacia lo objetivo, cuyas representaciones, advierten Carrizo y León (2011, p. 22), no son sino meros simulacros de ella.

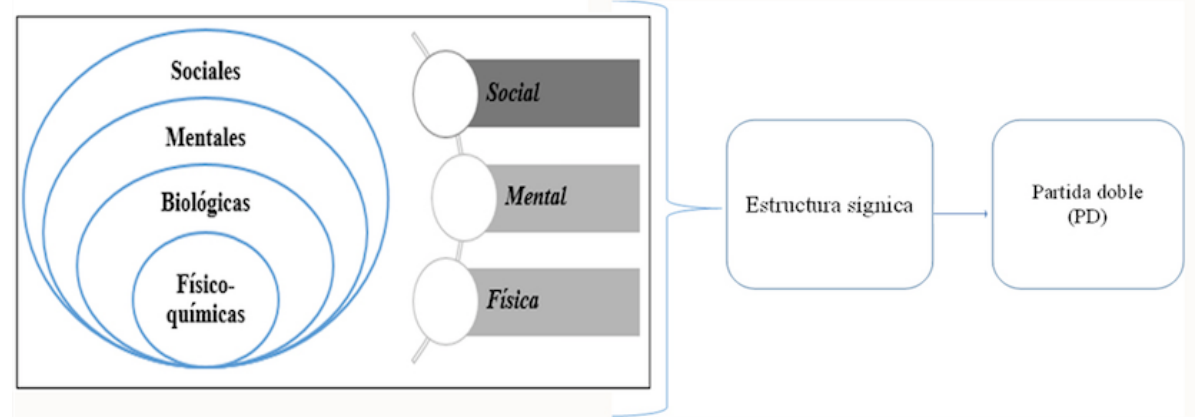

FIGURA 1

Fenómenos de la realidad representados en contabilidad

Fuente: elaboración propia con base en Mattessich (2006); Carrizo y León (2011), y Loaiza-Robles (2005, 2007)

Otra interpretación para el caso de la contabilidad se puede encontrar en el trabajo de Loaiza-Robles (2005), quien presenta el triple fenómeno de la representación de la realidad que acaece en este campo disciplinal. Para esta autora, la contabilidad pertenece sin lugar a dudas 
a la realidad física, social y mental, donde parte del hecho de que conceptos como derechos de propiedad, deudas y obligaciones sociales, son reales, es decir, la riqueza es una realidad física (estructura económica) y la propiedad es una realidad social (estructura financiera), que se pueden representar mentalmente y verificar de forma empírica. (pp. 62-63) (ver Figura 4 más adelante).

Para este documento, nos apoyaremos sobre esta asunción de realidad que considera, además, que la representación contable "cumple una función simbólica" (Loaiza-Robles, 2007, p. 8) dada por medio de la estructura sígnica de la PD (ver Figura 1).

Para el caso particular de los AI, debe considerarse que elementos inmateriales como los conocimientos de las personas, las relaciones con los clientes y proveedores, y el goodwill, entre una amplia variedad de elementos (capitales) intangibles, no exhiben una representación o estructuración objetiva en la contabilidad, bien fuera como activos o pasivos, ya que tales elementos -entre otros-, son el fruto del establecimiento de relaciones e interacciones entre los individuos de una sociedad. En consecuencia, cabe la posibilidad de considerar que los hechos que intenta reflejar la contabilidad no ofrezcan la misma verificabilidad o fiabilidad que, en contraste, sí se pueden encontrar entre los activos materiales. En otras palabras, en el contexto representativo de la contabilidad financiera de los AI, la ontología de la realidad es supremamente difusa.

\subsection{Encuadre epistemológico}

La determinación del encuadre epistemológico sobre la contabilidad ha constituido una tarea titánica sobre la cual la literatura especializada aún evidencia una amplia discusión: controversia que no parece estar acabada (Tascón-Fernández, 1997; Cuadrado \& Valmayor, 1999; Viloria, 2001; Bueno-Campos, 2004; Geba, 2004; Arenas \& Lavanderos, s.f.; García-Duque, 2004; Martínez-Pino, 2005, 2007; Mattessich, 2006; Nava, Ramírez, Méndez \& Sánchez, 2007; Araujo, 2007; Casal \& Viloria, 2007; Casal, Maldonado-Veloza, Peña, \& Viloria, 2010; Maldonado-Veloza, 2011). Así las cosas, son varios los encuadres o estatutos epistemológicos que se pueden encontrar para con la contabilidad.

De acuerdo con Carrizo y León (2011), es posible identificar al menos tres posturas epistemológicas con respecto a la contabilidad. En primer lugar, para una corriente de pensadores la contabilidad es una ciencia factual dedicada a la comprensión de la realidad, y a cuyos efectos desarrolla técnicas de medición para poder describirla; en segundo lugar, para otros es una tecnología social que permite reconocer, clasificar y medir un cierto segmento de la realidad; y en tercer lugar, para otros autores la contabilidad claramente representa una técnica (2011).

Para Herrscher (1979, 2002, citado en García-Casella, 2012), la contabilidad y su estatuto epistemológico pueden ser explicados bajo la imagen de una fábrica de ladrillos, debido a que con esta metáfora se pueden englobar los aspectos científicos, tecnológicos y técnicos que los componen. Para Herrscher, la fabricación de ladrillos abarca (a) principios de fabricación, (b) elementos técnicos, (c) el sistema de producción, (d) los procesos de fabricación de ladrillos y, por supuesto, (e) los ladrillos (ver Figura 2). 


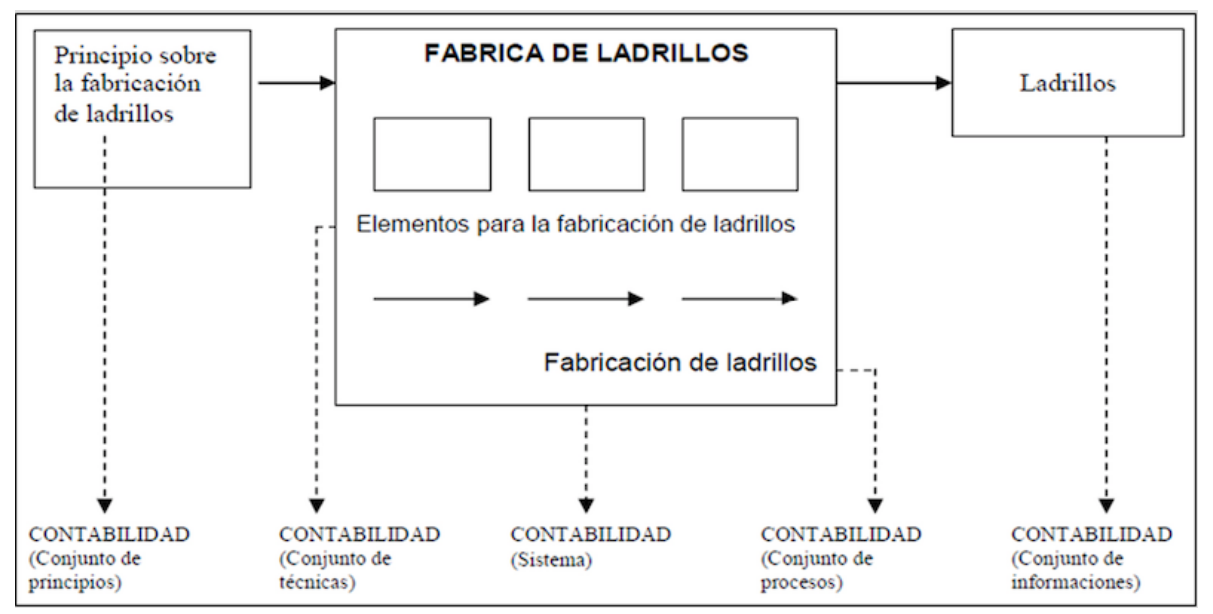

FIGURA 2

La contabilidad y la fabricación de ladrillos Fuente: García-Casella (2012, p. 3)

Para García-Casella (2012) la contabilidad no puede ser reducida a un solo estatuto, sino que debe observarse desde cinco puntos de vista: (1) principios (ciencia), (2) proceso de actividad (artesanía), (3) conjunto de elementos (técnica), (4) sistema, y (5) informes a emitir. No obstante, y en conclusión para este investigador, la posición epistemológica de la contabilidad es tanto la de una ciencia como la de una tecnología y una técnica (p. 3). A conclusiones similares llegan por separado Tua-Pereda (1995), quien realiza un recorrido por la evolución del concepto de contabilidad -y de paso por sus estatutos epistemológicos- a través de sus definiciones, y Cañibano (1999) quien, al hacer un análisis contable de la realidad económica, desentraña varios conceptos -y estatutos epistemológicos- de la contabilidad en su proposición del micro y macro análisis que le atañe.

En tanto, para Gómez-Villegas (2011), la contabilidad debe ser pensada fundamentalmente como una disciplina de tipo académico, ya que, además de estar en la universidad (la del proyecto ilustrado o la del training), envuelve un relativo avance en la investigación científica así como en la producción académica, dado que origina puentes entre las esferas teóricas y pragmáticas; efecto que ha allanado importantes "avances para el conocimiento socialmente útil" (p. 130), que facilitan el desarrollo social y humano. Ha sido tal el avance investigativo y, en particular, en el contexto anglosajón, que en lo últimos 10 años se han venido discutiendo los fundamentos intelectuales de la contabilidad interesados en "buscar construir teorías y modelos teóricos, sobre el rol, [y] el papel, que la contabilidad desempeña en la sociedad, en las organizaciones y en los mercados" (p. 131).

En este orden de ideas, trascendiendo el encuadre en que se encuentre la contabilidad, se puede decir que la mayoría de los autores coinciden de alguna u otra forma en la existencia de un problema central el cual, en términos de Carrizo y León (2011), corresponde a la producción de información "acerca de la realidad en la que se encuentra un determinado ente económico en cuestión” (p. 19). Así pues, la información que es generada por el sistema contable no solo se encarga de describir "tres aspectos de la realidad de un ente (realidad patrimonial, económica y financiera), sino que generará decisiones que podrían modificar la realidad empresarial y la de su contexto"; determinaciones cuyo fin es utilizar la información con algún propósito (p. 20). ${ }^{2}$ En consonancia, para propósitos de este documento se comprenderá la contabilidad como un cuerpo (trans) (multi)disciplinal de conocimientos. Por otra parte, lo que atañe a los AI será explorado en el tercer apartado. 


\subsection{Encuadre metodológico}

De acuerdo con Burbano (1989), no existe un único objeto y método de estudio en contabilidad, sino que son varios los métodos que se pueden observar a lo largo de su evolución histórica: en la Edad Antigua, el método "radicaba en el ejercicio de unas prácticas con un sistema operativo que poco contribuía a la estructuración de un conocimiento teórico" (p. 5). En la Edad Media, si bien no existía un desarrollo teórico relativo o profundo, ya se habían configurado procedimientos y métodos como la partida simple y la PD para "registrar los datos contables que tendiesen hacia la producción de resultados semejantes” (p. 7) así como para procesar la información económica que generaban las organizaciones empresariales.

En la Edad Moderna se observan los primeros intentos de teorización de la PD con la emergencia de "diferentes escuelas interesadas en el desarrollo científico de la contabilidad" (Burbano, 1989, p. 9). Entre dichas escuelas se destacan la Toscana, Lombarda y Veneciana, lo cual significa un incremento sustancial en materia de producción de literatura contable en países como Italia, Alemania, Inglaterra, Francia, España y los Países Bajos. Según Hendriksen (1974) y Burbano (1989), en la Edad Contemporánea se encuentran los primeros desarrollos metodológicos y teóricos que fueron aplicados a la contabilidad, tales como las teorías de la personificación, jurídica, económica, de la contabilidad pura y la administrativa, cuyos métodos inicialmente condujeron al uso del método científico de las ciencias. Lo anterior confirió un espacio para el surgimiento de la corriente positivista de investigación contable (Whitley, 2011; Cuadrado \& Valmayor, 1999) y dio lugar a la adecuación de los enfoques metodológicos lakatosianos y kuhnianos de los programas y paradigmas de investigación en contabilidad: contexto en el que se destacan los aportes de Cañibano y Belkaoui, respectivamente (Larrinaga, 1999). La postulación de los últimos enfoques metodológicos permite entrever el uso de otros caminos por medio de los cuales el investigador contable intenta acercarse, de una manera alternativa a la corriente positivista, y a la comprensión y la explicación de la realidad, con el fin de producir conocimiento en este campo disciplinal.

Otra postura corresponde a Ospina-Zapata (2006), quien señala que la contabilidad posee una metodología propia para vehicular y transportar los hechos económicos a un lenguaje específico. Esta metodología de finales de la Edad Media corresponde a la partida doble (PD), la cual "presupone una percepción de la realidad en la que los hechos y fenómenos se manifiestan o proceden en una forma dual" ( $p$. 164). Sin embargo, Ospina-Zapata advierte que esta no debe ser confundida con la dualidad, la cual es "el mecanismo de incorporación, clasificación y racionalidad con la que los hechos socioeconómicos son afirmados para el sistema económico vigente", mientras que la PD es "el sistema de reglas que permiten representar el hecho socio-económico y convertirlo en el hecho contable” (2006, p. 164) a través de una serie de cuentas. Las cuentas son, a cuño de este autor, "algo así como las palabras con las que podemos nombrar las realidades, y sus dinámicas y descripciones” (2006, p. 165), es decir: la estructura que permite (re)producir el hecho contable.

En el caso de los AI, la revisión de la literatura sugiere que no existe ni un método único ni un consenso entre los expertos respecto de la escogencia del mejor método de valoración de AI. A contrario sensu, se encuentra una amplia variedad de metodologías que reconoce hasta 46 formas (entre métodos y modelos financieros y no financieros) idóneas para valorar este tipo de activos que adoptan como bases metodológicas las ya clásicas técnicas como la Q de Tobin (1950), el Dow Chemical (1994), el Skandia Navigator (1994), el modelo West Ontario (1996), el Techonology Broker (1996), el Intangible Asset Monitor (1997), el ICIndex (1997), y el Modelo Intelect (Euroforum) (1998), entre otras. De acuerdo con Álvarez-Villanueva (2010), las metodologías de valoración restantes constituyen simples variaciones más o menos innovadoras de las técnicas clásicas o fundantes ya indicadas, postura a la cual nos sumamos luego de explorar con alguna profundidad la literatura especializada indicada. 


\section{La revelación en contabilidad y la pluri-nocionalidad de la representación}

Para Gil (2008), los modelos-estados contables son estructuras que permiten convertir la realidad en información, mediante un proceso semiótico de transformación: proceso que el autor denomina revelación (p.3).

En el marco normativo de la contabilidad y en el contexto nacional, el Capítulo III del Decreto 2649 (1993) contiene las normas técnicas que especifican las revelaciones que deben contener los estados financieros básicos, los consolidados, sus notas y las cuentas de orden correspondientes. En el Artículo 15 de ese capítulo, se expone lo relativo a la revelación plena: se establece que "el ente económico debe informar en forma completa, aunque resumida, todo aquello que sea necesario para comprender y evaluar correctamente su situación financiera [y] los cambios que ésta hubiere experimentado" (p. 41). En el contexto internacional y, en concreto, en el plano anglosajón, se encuentra una amalgama de nociones y de usos alusivos a este concepto, como se puede constatar en las normas internacionales de contabilidad (NIC), las normas internacionales de información financiera (NIIF), y las normas internacionales de auditoría y aseguramiento de la información (NIA). Por ejemplo, en el marco conceptual de las NIIF (IFRS, 2015), en el séptimo capítulo -que versa sobre la información a revelar como herramientas de comunicación, y su presentación-, se establece que los estados financieros expongan la información que es relevante para los usuarios: en concreto, se señala que "la comunicación eficiente y eficaz de esa información mejora su relevancia y contribuye a una representación fiel de los activos, pasivos, patrimonio, ingresos y gastos", lo cual eleva el grado de comprensibilidad y comparabilidad de la información en los estados financieros (p. 60).

En el caso de lo intangible, la NIC 38 (IFRS, 2014) exige la revelación específica de información que versa sobre este tipo de activos con respecto a sus vidas útiles (definidas o no), los métodos de amortización y revaluación, así como el importe en libros a valores razonables y la agregación/desagragación de la naturaleza de sus clases. No obstante, no es de interés en este documento realizar un análisis del tratamiento contable que exigen estas normas sobre los AI, ya que otros estudios se han ocupado de ello anteriormente (Hincapié, 2011; Hincapié \& Rincón, 2016). Por el contrario, el objetivo de este apartado comprende el proceso de revelación de información en la contabilidad financiera, entendido como el resultado de las tres fases que lo anteceden: la representación, la medición y la valoración.

\subsection{Representación1: representación semiótica}

En este punto resulta necesario advertir que la noción de representación ostenta en las disciplinas humanas y sociales, y, fundamentalmente, en el campo de la contabilidad, una pluri-nocionalidad similar a la que se indicaba con la idea de realidad: este concepto presenta una ontología difusa que se sujeta al contexto en el que sea utilizado (X representa Y en Z) (Scheutz, 1999). En ese sentido, referirse al concepto de representación en contabilidad implica observarlo por lo menos desde dos de sus múltiples estadios ontológicos y teóricos: el primero, referido a su aspecto semántico, y el segundo, a su funcionalidad (ver Figura 3).

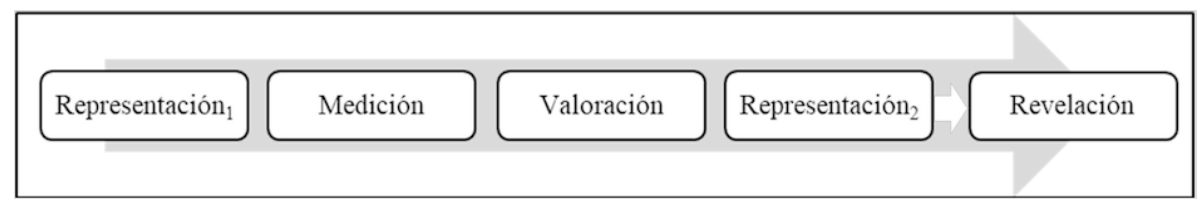

FIGURA 3

Proceso de revelación de información contable

Fuente: elaboración propia 
El primer estadio de la representación se plantea desde una perspectiva consonante con las teorías semióticas y refiere a la representación que se realiza en cabeza de los conceptos. De acuerdo con Barité-Roqueta (2000), en toda conceptualización es posible identificar dos caras de un concepto: una cara interna, que comprende y refiere al conjunto de enunciados que definen a ese concepto, y una cara externa, "que corresponde a la palabra, el conjunto de palabras u otro tipo de símbolos que identificará y representará al concepto" (p. 41). En términos de Deleuze y Guattari (1993), cada concepto tiene dos componentes: uno endoconsistente, que vuelca la mirada hacia los componentes inseparables dentro de él, y uno exoconsistente, que realiza un "sobrevuelo sobre sus componentes heterogéneos" (p. 26). A estas mismas indicaciones se suma Mardones (1991) cuando se refiere a la intensión, entendida como el aspecto interno del concepto, y la extensión, comprendida como su aspecto externo.

\subsection{Medición}

La medición, por otro lado, es "el proceso de asignar números en escala para ítems, de tal modo que la relación que existe en realidad entre los posibles estados de una variable son reflejados en relaciones entre números en la escala" (Swanborn, 1981, citado en González-González, 2013, p. 39). En otros términos, lo que la medición formula es una comparación entre cantidades con respecto a una unidad de medida definida, con el fin de averiguar cuántas veces una medida determinada se encuentra contenida en otra.

Para García, Limone y Álvarez (1988), el concepto de medida implica distinguir los siguientes aspectos: (1) el objeto de medición, (2) el instrumento de medición y (3) la unidad de medida. En el caso contable, para estos autores "lo que generalmente se miden son estados, esto es, [el] conjunto de valores que asumen las variables que permiten caracterizar una propiedad en un momento determinado de tiempo" (p. 93). El instrumento de medición por excelencia en contabilidad ha sido el Balance General, el cual constituye todo un sistema complejo en el que se interrelacionan otros subsistemas de medición. En tanto, la unidad de medida ha sido dada en magnitudes monetarias, es decir, "en cantidades físicas multiplicadas por el precio", rasgo que necesariamente produce una distorsión sobre lo medido si se consideran dos periodos de tiempo (p. 95).

Según García et al. (1988), existen dos tipos de medidas: unas primarias y otras secundarias. Las primarias "tienen por objeto establecer la cuantía de cada clase de bienes poseídos por la empresa en un momento dado" del lapso disponible, respetando la naturaleza del bien en cuestión, en tanto que las secundarias "son una conversión de las primarias a una unidad homogénea” (p. 96). En cuanto a las últimas cabe añadir que, en el caso de la contabilidad, el medio que facilita la realización de transacciones económicas es la moneda, la cual se obtiene de multiplicar el vector cantidad (establecido como medida primaria) por el vector precio (p. 97). La ventaja de esta forma de cálculo, indican los autores, obedece a que fundamentalmente permite la utilización de distintos criterios de valoración (ver Figura 4), tal como se indicó en el apartado 1.3. 


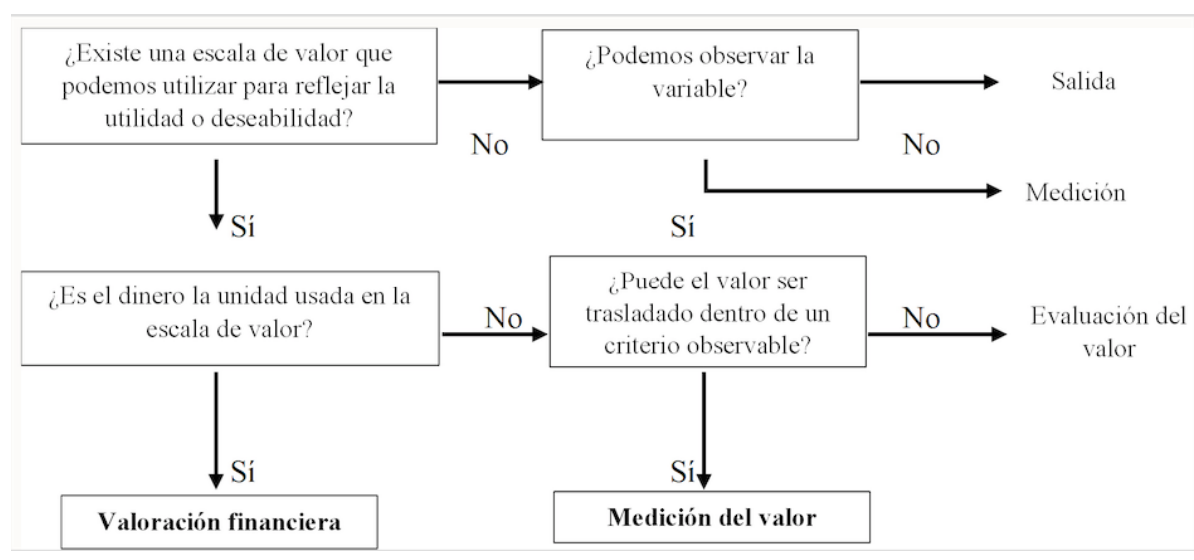

FIGURA 4

Valoración financiera, medición del valor, evaluación del valor y medición Fuente: Andriessen (2004, citado en González-González, 2013, p. 40)

\subsection{Valoración}

Valorar, para el Diccionario de la Real Academia Española (2016), es la acción de "señalar el precio de algo". Para Rescher (1969, citado en González-González, 2013), la valoración es "como una evaluación o medición comparativa de alguna cosa con respecto a su representación de un cierto valor"; cálculo que se puede realizar por medio de una escala de números ordinales -los que expresan orden- o cardinales -los cuales denotan cantidades-. En este sentido, González-González arguye que para realizar la valoración "se requiere de [a] un objeto para ser valorado, [b] una estructura para la valoración y [c] de un criterio que refleje la utilidado deseabilidad del objeto" (2013, p. 38, el énfasis es mío).

Existen al menos cuatro formas de determinar el valor según Andriessen (2004, citado en GonzálezGonzález, 2013), a saber: (1) se puede definir el criterio de valor en términos monetarios, en cuyo caso la determinación recaería sobre la valoración financiera; (2) se "puede usar un criterio no monetario y trasladarlo dentro de un fenómeno observable", en cuyo caso el método a utilizar es el de medir el valor; (3) si "el criterio no puede ser trasladado dentro de un fenómeno observable pero en cambio depende de un juicio personal" de un evaluador, se utilizaría el método de evaluación del valor; y (4) si "la estructura incluye un criterio para valorar, pero involucra una escala métrica que relaciona un fenómeno observable, entonces el método es de medición" (pp. 38-39, el énfasis es mío). ${ }^{3}$

\subsection{Representación2: representación contable (por partida doble)}

El segundo estadio de la representación que nos interesa estudiar encuentra asidero en la contabilidad por medio del esquema metodológico de la partida doble (PD). Sin embargo, antes de entrar a revisar este estadio, resulta pertinente abordar la noción de representación en el campo de la contabilidad. Para Machado (2011), el concepto de representación contable se orienta hacia la necesidad de volver a presentar "la realidad de las organizaciones, a crear constructos del mundo real y a sustituir la realidad (correlato) por dichos constructos mentales" (p. 161).

Bajo esta perspectiva, resultan fundamentales dos conceptos centrales que se articulan con el campo contable: el de modelo y el de sistema contable. En ese contexto, para Gómez-Villegas el modelo contable "es el conjunto de criterios que permiten la representación de las dinámicas económicas y transaccionales de una entidad (criterios de medición, criterios de valoración y criterios de mantenimiento de capital)" (2011, p. 140). Por otro lado, para Machado (2011) el sistema contable ha sido percibido como un conjunto de 
elementos que permiten la captura, identificación, clasificación, medición, registro y exposición de datos contables y, por tanto, la revelación de su constructo como "hechos contables" (p. 160).

En consecuencia, mucho antes de que se formulara la organización racional de las empresas y de que el trabajo se erigiese en técnica científica autónoma en la primera mitad del siglo XX, el hecho de la organización se impuso y la aplicación inconsciente de sus principios fue el motor de la evolución contable: tal fue el orden de los sucesos, tanto en la Edad Media (Vlaemminck, 1961) como hacia finales del siglo XVIII y comienzos del XIX, cuando la PD coadyuvó a la racionalidad y al controlismo del capitalismo industrial (Ariza, 2000). En el contexto de este asir técnico-instrumental, de acuerdo con Ospina-Zapata (2006), la contabilidad "se ubica como un tipo de conocimiento que tiene la posibilidad de presentar la circulación de los elementos que reunidos indican el flujo de la riqueza de una determinada forma organizativa y social” (p. 162).

Ahora bien, según Corvellec (2001), la representación en la contabilidad se da mediante la técnica de la PD. Al respecto, plantea que la contabilidad hecha de acuerdo con esa técnica es una "forma dinámica de representación cuidadosamente estandarizada y hasta normativa” (p. 4) que ha sido desde sus inicios una "forma acabada de representar para el arte de ganar dinero, y hasta el presente no ha necesitado cambiar". Asimismo, arguye que la contabilidad por PD "no plantea la pregunta del por qué", sino que "da una respuesta pragmática a las preguntas de para quién, qué, cómo y cuándo se gana dinero pero deja de lado el por qué” (p. 6).

En esta misma dirección semántica -aunque contraria a las posiciones anteriormente expuestas- se encuentra Loaiza-Robles (2007), quien plantea que la PD no es una forma de representación, "sino que es un signo que cuenta con una estructura conceptual que avanza a la par con los desarrollos sociales"; un factor en el que la realidad no se significa por sí sola sino que "se le construye el sentido usando sistemas representacionales como conceptos y lenguajes" (p. 11). En ese contexto, el sentido de la contabilidad depende de su función simbólica y, sin lugar a dudas, es la PD la que resulta ser su signo más representativo.

Según Loaiza-Robles (2007), en la contabilidad las formas de representación han estado ligadas a las aplicaciones matemáticas, tal como se puede observar en la figura 5. En otras palabras, existen diferentes formas de representación que corresponden a la PD “ya que manifiestan la dualidad existente entre riqueza y propiedad y todas las relaciones que allí subyacen”. Así las cosas, Loaiza-Robles manifiesta que la construcción de nuevas formas de representación de la PD cumple dos funciones: "la primera, encaminada al análisis de estructuras teóricas referidas a la relación riqueza-propiedad dada en las organizaciones, y la segunda, como valioso instrumento de información que agiliza el proceso de toma de decisiones” (p. 20). 


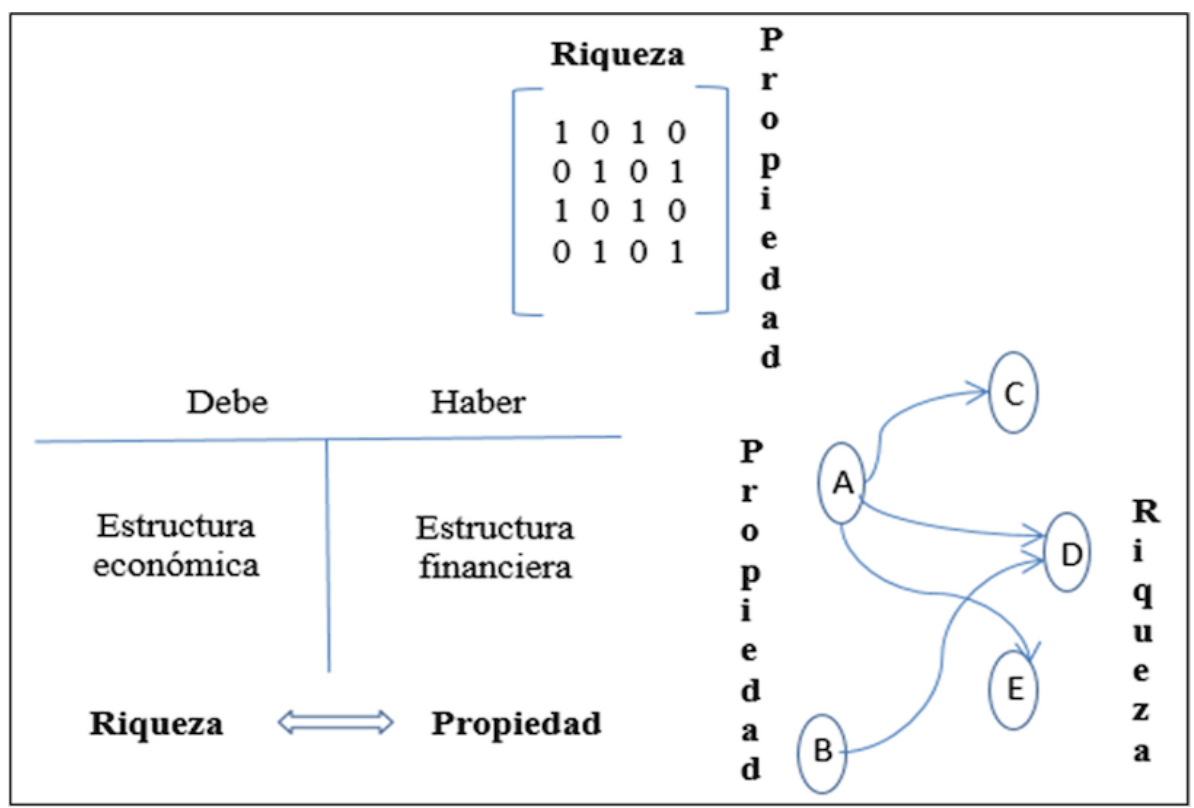

FIGURA 5

Formas de presentación en contabilidad a la luz de la PD

Fuente: Loaiza-Robles (2007, p. 19)

En términos más específicos, es posible encontrar la representación contable de lo intangible en los documentos reglamentarios del campo disciplinal en el contexto nacional y en el internacional. En el primer contexto, el Decreto 2160 (1986) y, posteriormente, los Decretos Reglamentarios 2649 y 2650 (1993), formulan los lineamientos esenciales y ofrecen algunas luces con respecto a los principios contables y las normas técnicas generales y específicas aplicables a los activos, pasivos y al patrimonio. Asimismo, aportan una importante fundamentación a la práctica contable, así como a la tipificación y descripción de la dinámica que integra, respectivamente, sus componentes legales.

En el escenario anglosajón cabe aludir en concreto a la NIC 38 (IFRS, 2014): en esta norma se plantean los parámetros fundamentales para identificar, reconocer, medir, valorar y revelar a los stakeholders información relacionada con la inmaterialidad de recursos de tal tipo que sobre ellos se espera la obtención de beneficios económicos futuros. Con lo expuesto hasta ahora, se ofrece al lector de manera holística un panorama de lo que se mide, valora, representa y revela en la contabilidad financiera en general y, en particular, de lo que atañe a los AI.

A continuación, se desarrollará una necesaria caracterización de los AI que, se espera, constituya, por un lado, una antesala introductoria de elementos a considerar en la construcción de un marco teórico de estudio de lo intangible en la contabilidad, y por el otro, abra paso a la observación de una serie de críticas que subyacen en la pluralidad de discursos que se imbrican en la contabilidad financiera respecto de la representación contable y la revelación de los AI.

\section{Definición y caracterización de los activos intangibles (AI)}

Un activo, esgrimen Sprouse y Moonitz (citados en Vlaemminck, 1961), representa beneficios económicos futuros esperados cuyos derechos ha adquirido la empresa como resultado de alguna transacción pasada o corriente. De acuerdo con los autores, lo que caracteriza a un activo es (1) que exige la existencia de un derecho específico a beneficios futuros o servicios potenciales; (2) que tales derechos tienen que acumularse 
a favor de una persona o empresa específica, es decir, enfatizan el control de los recursos de la entidad; y (3) adicionalmente, que tiene que haber una reclamación legalmente exigible a los derechos o servicios (p. 293).

Los intangibles se caracterizan por ser un conjunto de atributos que "carecen de sustancia física y/o actitudes financieras/monetarias, tienen una rendición de cuentas parcial, reclaman el ingreso de beneficios futuros, tienen una negociabilidad limitada y un mercado parcialmente ausente" (Kaufmann y Schneider, 2004, p. 375). ${ }^{4}$ De igual forma, en la revisión de alguna literatura ${ }^{5}$ se encontró que en la mayoría de los casos el término intangible es utilizado como sinónimo de capital intelectual (CI), activo intangible (AI), propiedad intelectual (PI), o contabilidad del conocimiento, entre otra variedad de denominaciones.

Para otros autores, el término intangible simplemente es utilizado para hacer referencia al conocimiento y/ o a la exigibilidad de derechos sobre beneficios económicos futuros. En tanto, para otros más, lo intangible llega de hecho a constituir un nuevo factor de producción que encabeza los factores clásicos de la tierra, el trabajo y el capital, que abre paso a nuevos estadios en la sociedad postcapitalista, como al del capitalismo cognitivo (Drucker, 1994; Tissen, Andriessen, \& Deprez, 2000; Quijano-Valencia, 2005; Archel-Domench \& Gómez-Villegas, 2014).

En ese sentido, el mapa conceptual 1 intenta condensar y esquematizar un puñado de nociones que se encuentran entre la literatura contable y administrativa que atañe al concepto de intangibles. La clasificación ofrecida busca identificar sus puntos de convergencia y discrepancia, así como el enfoque que persiguen sus definiciones. Son tres las esferas en las que se ha divido esta literatura: la primera pretende recoger los fundamentos teóricos expuestos en el acervo bibliográfico; en la segunda se sintetizan las diferentes aproximaciones que los organismos reguladores de la profesión contable han normalizado como de tipo científica y/o instituido como de general aceptación, y en el tercer grupo se distinguen los intangibles que no son concebidos como activos o capitales, sino como un tipo de recurso auxiliar que contribuye en la generación directa/indirecta de ventajas competitivas (ver Anexo 1: mapa conceptual). ${ }^{6}$

En cuanto a las definiciones institucionalizadas o de general aceptación, interesa exponer lo establecido en el contexto nacional por el Decreto Reglamentario 2649 (1993) y, en el frente internacional, lo indicado en la NIC 38 (IFRS, 2014). Según el Decreto Reglamentario 2649 (1993), los AI son aquellos recursos que han sido obtenidos por un ente económico y que, careciendo de naturaleza material, implican un derecho o privilegio oponible a terceros de cuyo ejercicio o explotación se espera obtener beneficios económicos en varios periodos determinables (Artículo 66, p. 59). En tanto, de acuerdo con la NIC 38, un activo intangible es un activo identificable de carácter no monetario y sin apariencia física que debe ser controlado por una entidad como resultado de sucesos pasados, y del cual se espera obtener beneficios económicos en el futuro (IFRS, 2014, pár. 8, p. 1249).

Según Zambon (2016), otro tipo de características que arroja la revisión de la literatura (ver Figura 6) acerca de los activos intangibles (AI) es que durante los últimos 20 años de investigación tal concepto ha sido utilizado para referir una amplia variedad de términos como la innovación, la investigación y desarrollo (I+D), al igual que la gestión, el capital organizacional, el capital humano, el capital socialrelacional y/o para medir el desempeño corporativo. Sin embargo, en los últimos 10 años los estudios sobre los AI y el CI han experimentado tal incremento en los círculos académicos, profesionales y empresariales, que ha dado lugar para el surgimiento de un "nuevo campo" o "área disciplinaria" (p. 3), así como la especialización de plataformas académicas como: Journal of Intellectual Capital; International Journal of Learning and Intellectual Capital; VINE, y Knowledge Management Research and Practice. De igual forma, ha aventurado espacios en las revistas: Abacus; Accounting, Auditing, Accountability Journal (AAAJ); Academy of Management Journal (AMJ); Academy of Management Review (AMR); Administrative Science Quarterly (ASQ); Harvard Business Review (HBR); Journal of International Business Studies (JIBS), o Strategic Management Journal (SMJ), según Kaufmann y Schneider (2004, p. 368). 


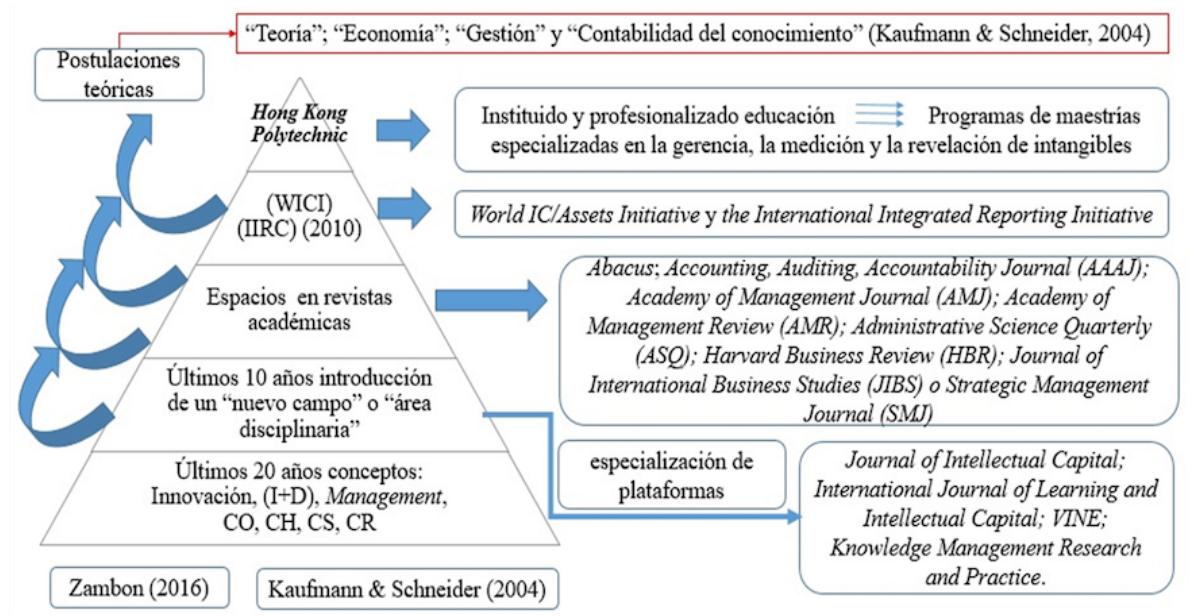

FIGURA 6

Características de AI en la revisión de literatura

Fuente: elaborado a partir de Kaufmann y Schneider (2004), y Zambon (2016).

Para diferentes ramas de la contabilidad como la financiera, la fiscal, la de gestión y la de control, los AI pueden representar aproximadamente entre el cincuenta y el cien por ciento del valor adicional de una empresa con respecto a su valor en libros (Brooking, 1997; Edvinsson \& Malone, 1997; Roos et al., 1997; VargasMontoya, 2000); valor que en muchas ocasiones no es reconocido, revelado o explicado por el modelo estático contable (Cañibano et al., 1999; Bueno-Campos et al., 2001; Corvellec, 2001; Peña \& Ruiz, 2002; Machado, 2004, 2011; Carrizo \& León, 2011). Por el contrario, y como sostienen algunos autores, tal valor de hecho requiere otros medios de representación y comunicación (Enríquez \& Alcalá, 2003; Kaplan et al., 2006; Loaiza-Robles, 2005, 2007; Ramírez-Ospina, 2007; Banguero \& Castillo, 2009; Álvarez-Villanueva, 2010; González-González, 2013).

En un nivel mucho más avanzado, el auge en los estudios sobre los AI y el capital intelectual (CI) ha dado lugar a la creación de organizaciones internacionales como The World IC/Assets Initiative (WICI) y The International Integrated Reporting Initiative (IIRC); organizaciones que, aproximadamente desde el año 2010 hasta la fecha, proponen un "nuevo marco para el reporte de intangibles" y que promueven "nuevas definiciones y categorización de intangibles" (Zambon, 2016, p. 4), respectivamente. Por otro lado, y en un nivel superior al anterior, Zambon arguye que, por ejemplo, en el Hong Kong Polytechnic, se ha institucionalizado y profesionalizado tanto la educación en esta área, que ha dado lugar a la creación de algunos programas de maestrías especializadas en la gerencia, la medición y la revelación de intangibles (2016, p. 4).

En síntesis, los últimos 10 años de investigación sobre intangibles ha proveído importantes aportes. A cuño de Kaufmann y Schneider (2004), algunas publicaciones que han enfatizado en los activos intangibles (AI), el capital intelectual (CI), la propiedad intelectual (PI), el capital intangible y los recursos intangibles (p. 374), han develado una amplia variedad de grupos y categorizaciones que estructuran modelos para medir y revelar información que ayuda a la gerencia en la toma de decisiones financieras (p. 378) -si esta así lo desea o considera pertinente-. Asimismo, han dado pie a la postulación de propuestas teóricas entre las que se destacan la "teoría del conocimiento", la "economía del conocimiento", la "gestión del conocimiento" y la "contabilidad del conocimiento" (p. 382), entre otras que abordan orientaciones internas y externas de la medición, gestión y valoración de intangibles.

Luego de la caracterización de los AI desarrollada, a continuación, se presentarán algunas críticas referidas al actual periodo de crisis que exhiben los activos de este tipo junto con la contabilidad, con la expectativa de que su advertencia posibilite ulteriores construcciones que enmarquen el estudio fundamentado de ambos. 


\section{Algunas crisis en contabilidad y los activos intangibles (AI)}

Según el esquema lógico-deductivo desarrollado en la estructura expositiva de este documento, se clasifica en tres apartados una serie de críticas que han intentado socavar los esquemas teóricos, metodológicos, ontológicos y epistemológicos que atañen al campo y que subyacen en algún manojo de discursos situados, en general, en la contabilidad, y, de forma particular, en los AI.

\subsection{Sobre la categorización/conceptualización}

- De acuerdo con García (1997 citado en Machado, 2009), "la contabilidad convencional ha introducido una gran rigidez en su armazón conceptual, de modo que hoy ni siquiera puede dar cuenta cabal de la cada vez más compleja economía de los negocios” (p. 48), así como de la llamada revolución informática o del capitalismo cognitivo. De igual forma, Machado (2009) advierte sobre la inclusión de esquemas o modelos mentales previos que inciden directamente en las teorías que "determinan el tipo de representación que se desea obtener, al preferir uno u otro modelo, método o forma de representación con sus respectivas descripciones, explicaciones, contexto y productos finales" (p. 48).

- Según Reilly (2011) es igualmente relevante analizar el hecho de que en las ciencias o disciplinas sociales y humanas se haga uso del método científico positivista proveniente de las ciencias naturales, y que se espere obtener la misma validez y verosimilitud que resulta en estas. Lo anterior evidencia una incompatibilidad de criterios epistémicos y metodológicos, como enfatizan De la Garza-Toledo (1987), Mardones (1991) y Cabruja, Íñiguez y Vázquez (2000).

- En una coincidencia con el pensamiento contemporáneo de Gómez-Villegas (2010) y Gracia (2009), Vlaemminck (1961) ya había señalado que mucha de la literatura en y sobre contabilidad se ha visto altamente "influenciada por la evolución del hecho contable en las empresas" (1961, p. 109). Lo anterior quiere decir que el modelo pedagógico, impreso en la enseñanza de la contabilidad generación tras generación, ha bebido de las experiencias acaecidas en el entorno organizacional, y ello ha influenciado en demasía a los primeros maestros, autores, profesionales e investigadores de la contabilidad en sus procesos de formación o deformación en la población estudiantil (Cubides, 1999; Sierra-González, 2001; Quijano-Valencia, 2002; Rojas, 1996, 2009; Gil, 2010; Machado, 2011; Quinche-Martín, 2011, 2012; Bustamante-García, 2013).

- A la fecha, lo intangible solo tienen un reconocimiento de orden legal y exhibe una subvaloración en la contabilidad financiera (Hincapié, 2011).

- Una crítica al campo de la gestión de intangibles obedece a la falta de construcciones teóricas que no estén basadas en modelos o marcos existentes, y que permitan explicar cómo se gerencia, acumula y preservan los intangibles. En concreto, Kaufmann y Schneider (2004) plantean que la "investigación del campo intangible debe concentrarse mucho más en los enfoques teoréticos que permitan explicar las funciones de los intangibles"; en cómo se establecen sus categorías, o en cómo se puede transferir alguna clase específica de intangibles (p. 384).

- De igual forma, estos autores también arguyen que "la discusión de intangibles necesita tener un enfoque mucho más específico" (Kaufmann y Schneider, 2004, p. 384); por ejemplo, la discusión de intangibles es completamente diferente cuando la información es necesitada por stakeholders internos o externos. En esta misma línea, se encuentra un vacío en la literatura con respecto a la especificidad en las reglas de cómo los recursos permiten la generación de ingresos futuros, y de las diferentes formas de medir y visualizar los intangibles (Colombia, Decreto Reglamentario 2649, 1993; Edvinsson \& 
Malone, 1997; IFRS, 2014). Lo mismo se observa en la determinación del criterio de razonabilidad de la información contable (Hincapié \& Rincón, 2016).

\subsection{Sobre la medición y la valoración}

- La mayor crítica que se observa en gran parte de la literatura académica y regulativa en el contexto nacional e internacional va dirigida hacia la no distinción de estos procesos, dado que se llega incluso a interpretar la noción de medición como sinónima de la valoración, y esta última, a su vez, como revelación. Por ejemplo, Gil señala que al registrar el valor -entendido como cualidad esencial de los bienes y derechos-- utilizando la moneda -comprendida como unidad de cuenta transaccional derivada del intercambio-, se confunde el criterio de medición con la unidad de cuenta, lo cual significa que la moneda, además de operar como "signo convencional" (2008, p. 4), también oculta la realidad. Por tanto, para que los estados contables puedan revelar información y describir la realidad tal cual es, "deberían expresarse en términos no monetarios" (p. 6).

- En el caso de los AI, dos importantes críticas subyacen en el discurso normativo que las integra: la primera se refiere a la difícil labor de determinar una unidad de medida, así como a la adecuada escogencia de un instrumento de medición. Por otra parte, la segunda crítica comprende el proceso valorativo con el que se reconoce la fuerte impresión y presencia de tensiones (inter)subjetivas, dado que en el mercado se pueden encontrar, al menos, 46 diferentes formas de estimar y conferir un precio a un ente inmaterial.

Recordemos que la medición implica una comparación de objetos o magnitudes, mientras que la valoración remite a una estimación desarrollada de acuerdo con la deseabilidad de un objeto (González-González, 2013). En ese sentido, epistemológica y metodológicamente existiría una incoherencia en el discurso positivista de la contabilidad con respecto a la defensa del uso de métodos devenidos de las ciencias naturales; métodos que, se espera, arrojen resultados objetivos, verídicos e infalibles para valorar los diferentes recursos organizacionales. Sin embargo, y a contrario sensu, este proceso estimativo o especulativo dista ampliamente de reflejar isomórficamente la realidad de lo que acontece en los planos económicos, legales, financieros, ambientales y sociales del entorno organizacional.

- De acuerdo con lo anterior, resulta evidente que la asignación de los precios en contabilidad para transar elementos reconocidos y clasificados como AI, es un proceso completamente especulativo (subjetivo) que podría distorsionar la revelación y representación -en diferentes periodos de tiempode la situación económica, legal y financiera que busca reflejar la información contable por medio de la PD.

- Con respecto a la partida doble (PD) como método de representación de la contabilidad, la literatura sugiere que este esquema no es el más adecuado para exponer y revelar información de los AI. Lo anterior se debe a que tal método se instituye como la respuesta a las necesidades de información de un contexto basado en los elementos materiales, pero, en la contemporaneidad de los negocios inmateriales, resulta esencialmente obsoleto.

- En cuanto a los AI, Kaufmann y Schneider (2004) señalan que, en su mayoría, los modelos propuestos para la medición y el gerenciamiento de intangibles están basados en una serie de estimaciones y afirmaciones, así como en una variedad de definiciones que reflejan la escogencia de alguna arbitrariedad conceptual y metodológica; arbitrariedad según la cual los modelos implementados dan como resultado una amplia variedad de resultados estimados (p. 383). 


\subsection{Sobre la representación por partida doble (PD) y la revelación}

- Para Corvellec el problema que enfrenta hoy en día la contabilidad por partida doble (PD) es la descripción del capitalismo actual (2001, p. 7). En otras palabras, este tipo de contabilidad se inventó para describir las actividades comerciales y se desarrolló para describir la economía industrial, no una economía virtual como la actual. Otra limitación que se observa en la revisión a la literatura corresponde a la crisis de la representación contable; al respecto, es Machado quien señala en su conclusión que:

La problemática de la representación contable se centra en dos aspectos: en primer lugar, el debate ontológico acerca de la realidad de la cual debe dar cuenta la contabilidad. En segundo lugar, el debate metodológico en torno a la capacidad representativa de la partida doble convencional (como la aplicación triunfante y vigente en la práctica), y de las alternativas presentadas por diversos autores (propuestas emergentes), tales como la contabilidad matricial, sagital, vectorial y basada en el análisis circulatorio, entre otras. (2009, p. 53)

- En tanto, para Loaiza-Robles (2005) el problema que exhibe la contabilidad orbita en torno a la partida doble (PD) como su instrumento de representación. En particular, señala que pese a que la PD cumpla las funciones de análisis estructural de la relación riqueza-propiedad y sea, a su vez, un "valioso instrumento de información que agiliza el proceso de toma de decisiones", este método ha obstaculizado una comprensión más amplia de la relación de la disciplina con las demás ciencias sociales, "ya que solo se observa en ellas [en los hechos que captura, procesa y revela] la utilización de la matemática como herramienta y no se han dado los marcos teóricos y metodológicos que permitan una evaluación de los desarrollos formales en contabilidad" (p. 70, inciso mío).

- En esta dirección apuntan Carrizo y León (2011) al señalar que en todo proceso de conocimiento existe la mediación del lenguaje; no obstante, es sumamente difícil determinar si "ciertas entidades contables existen a partir de la aparición de la palabra que las nombra, o si la palabra es posterior a la existencia de la cosa, puesto que es el lenguaje quien nos da a conocer la cosa" (pp. 23-24). Asimismo, estos autores sugieren tener en consideración que "la 'realidad' que la contabilidad 'representa' queda definitivamente atada a los propósitos que persigue quien elabora, diseña y trasmite la información” (p. 25), es decir, debe sopesarse que, pese a que sea por medio de la PD que la contabilidad representa la realidad, existe una alta carga subjetiva que recae sobre quien realiza la representación contable. Este argumento confirma de alguna forma esa propuesta que Loaiza-Robles (2005) señalaba con respecto al triple fenómeno de representación de la realidad física, social y mental que se da mediante la PD, en contabilidad.

- Este mismo sentir se puede encontrar en el trabajo de Macintosh (2004, citado en Machado, 2009), quien señala que "la problemática de la contabilidad es una crisis de representación" (2009, p. 43) en la que esta no debe reflejar una realidad sino construirla con un sentido. Así las cosas, se advierte que el concepto de representación "parece no estar arraigado en los desarrollos de la teoría contable, llegando al caso en que no sólo no se le relaciona sino que se le confunde con los de registro, reconocimiento, revelación, valoración, agregación e información” (p. 45), lo cual acarrea un evidente estado de irreflexión ontológica y epistemológica del proceso de construcción y representación de la realidad en los sujetos e intérpretes contables. Asimismo, Machado sugiere considerar el dogmatismo con el que la contabilidad es concebida como el único horizonte que refleja la realidad financiera y económica de los entes contables, bajo la homologación de empresa con propietarios (p. 45).

- Para este autor en particular, son varios los motivos que -además de los inmediatamente expuestosconducen a una crisis de la representación contable: uno de los más representativos corresponde a la ausencia de isomorfismo con respecto a la realidad, que hace presumir o asumir como verdadera la información que la contabilidad expone por medio de sus formas o modelos de representación de la realidad de las organizaciones (Machado, 2009). De igual forma, Robles (2006, citado en Machado, 
2009) advierte al respecto de la capacidad representativa del balance que puede estar supeditada a "la relatividad que le imprime quien la elabora (el contable)" (p. 47). En ese sentido, Robles se refiere a este estado financiero como la "foto que será una representación más o menos fiel, dependiendo de la calidad de la cámara y de la creatividad del artista” (Machado, 2009, p. 47). En otras palabras, se hacen patentes cuestiones centrales como la subjetividad en las mediciones contables (Fernández \& Barbei, 2006), la capacidad deformadora del discurso contable (Archel, 2007) y la moneda como limitante de la representación y la revelación (Gil, 2008).

- "La representación contable es un proceso que ha sido limitado en la práctica contable a aspectos meramente instrumentales conexos con el uso de la partida doble", lo cual evidencia la necesidad de "realizar un salto cualitativo desde la aritmética simple hasta la implementación crítica de diversas teorías” (Machado, 2009, p. 49) que permitan dilucidar, desde otros marcos de interpretación, el fenómeno de la representación contable. A esta invitación también se suman Loaiza-Robles (2005, 2007), Keller (2011) y Quinche-Martín (2011, 2012), quienes sugieren que se contemplen los estudios cualitativos de investigación, y metodologías especializadas como la arqueología y el análisis de discurso, respectivamente.

- En términos de Macintosh (2004, citado en Machado, 2009) la crisis de la representación en contabilidad es el resultado de que la disciplina contable haya dejado de referirse a realidades o a cuestiones con referentes en el mundo real, lo cual implica, según Machado, un problema de tipo ontológico respecto de la realidad o del mundo real que la contabilidad representa (2009). En consonancia con lo anterior, Gracia, Ruíz y Agudelo (2013), concluyen que Macintosh

aborda el problema de la representación contable, pero no formula alternativas de solución. Su trabajo solo es deconstructivo pero no reconstructivo y, a partir de tal análisis, aduce que los grandes problemas se centran en la concepción de una realidad social como reflejo de la realidad material, pasando por alto que la realidad social es parte activa de la representación contable, en especial por lo que respecta a la valoración contable, ubicándola en la realidad material, lo cual es evidente en la histórica imbricación de los conceptos de medida y valor en todas las formulaciones que sustentan los marcos conceptuales y técnicas de representación que de ellos se derivan. (pp. 83-84)

\section{Conclusiones}

Son varias las conclusiones que se pueden derivan de la revisión de la literatura y la exploración temática desarrolladas. Con respecto a los aspectos ontológicos, epistemológicos y metodológicos de la representación en contabilidad y lo intangible, la revisión de la literatura sugiere la existencia de una manipulación ontoepistemológica que dificulta la determinación y delimitación categorial de este campo del conocimiento. Lo mismo se puede ver en las estructuras y figuras lingüísticas utilizadas en él. Por el lado metodológico, la literatura señala que la PD se perfila como el principal método que la contabilidad posee para representar y revelar diferentes segmentos de la realidad que acontecen (o simulan acontecer) en las organizaciones. Tal efecto es notable, a pesar de que este medio no explique el porqué de las acciones que ejecuta, exhiba un rígido armazón conceptual, y subsista en ella una marcada exposición a la subjetividad de quien lo utiliza.

En cuanto a la revelación, se observa que en el entretejido de los discursos subyacen capacidades y potencialidades latentes de revelación/ocultación (Gil, 2008). De acuerdo con lo anterior, los informes contables son estudiados como dispositivos retóricos que pueden manipular a los usuarios contables y/o posibilitan su gobierno (Archel, 2007; Quinche-Martín, 2012).

En el caso de los AI, la revisión de la literatura evidencia, por un lado, que conceptual y procedimentalmente la medición y la valoración no significan lo mismo. Lo anterior puede conducir al otorgamiento de una falsa objetividad y a la manipulación ontológica de la realidad (simulada) y de la información contable que se refleja en los estados financieros. Por otro lado, la literatura sugiere la inexistencia de una unidad de medida o un metodología común, o de un consenso entre los expertos con respecto a la escogencia del mejor método 
de valoración y revelación de información. De igual forma, la diáspora de intereses y esfuerzos distorsiona y dificulta -aún más- la elaboración de reglas específicas que permitan reconocer, medir, valorar, revelar y gerenciar los recursos intangibles que las organizaciones poseen/crean con el objeto de obtener beneficios económicos futuros y sostener sus ventajas competitivas en la actual virtualización de la economía.

Así las cosas, se considera que la observancia de -al menos- los anteriores elementos, abre una perspectiva que puede arrojar luces en la futura investigación sobre la construcción y consolidación de un marco teórico que concentre sus esfuerzos en obtener y proveer datos descriptivos y explicativos, sobre cómo construir y usar la información de los intangibles; marco que puede ser adaptado, por otro lado, a cada subclase especialmente, y a las necesidades elevadas de la gerencia de intangibles (Kaufmann y Schneider, 2004). Asimismo, se espera que dicha fundamentación teórica clarifique la jungla conceptual y metodológica que subyace en los procesos de medición y valoración del conocimiento (Bueno-Campos, 2004; Álvarez-Villanueva, 2010).

En ese sentido, el potencial de investigación resultaría altamente fructífero en este campo, si se llegasen a concentrar los esfuerzos de la comunidad académica, profesional y empresarial en asuntos específicos (como la identificación, la medición, la representación, la valoración o la revelación de AI). ${ }^{7}$ Así lo dejan entrever Kaufmann y Schneider (2004) y Zambon (2016), entre el amplio horizonte de información que se puede encontrar en esta revisión a la literatura.

\section{Agradecimientos}

Trabajo derivado del proyecto de investigación para optar por el título de Magíster en Contabilidad de la Universidad del Valle, dirigido por el profesor Jorge Manuel Gil (Argentina) y codireccionado por el profesor Leonardo Solarte Pazos (Colombia).

\section{Referencias}

Alama Salazar, E., De Castro, G., \& López Sáez, P. (2006). Capital intelectual. Una propuesta para clasificarlo y medirlo. Revista Latinoamericana de Administración, 37, 1(16).

Álvarez-Villanueva, C. (2010). Hacia un nuevo modelo de valoración de intangibles (Tesis doctoral). Universitat Jaume I, Castellón, España.

Andreou, A. N., Green, A., \& Stankosky, M. (2007). A framework of intangible valuation areas and antecedents. Journal of Intellectual Capital, 8(1), 52-75.

Araujo, J. A. (2007). Los recursos: objeto de estudio de la Contabilidad. Contaduría Universidad de Antioquia, (50), 177-186.

Archel, P. (2007). Discurso contable, ideología e informes anuales: Un enfoque interpretativo. Contaduría Universidad de Antioquia, (51), 41-64.

Archel, P. \& Gómez-Villegas, M. (2014). Crisis de la valoración contable en el capitalismo cognitivo. Innovar, 24(52), 103-116.

Arenas, T. \& Lavanderos, L. (s.f.). Capital Intelectual;Objeto o proceso?: Hacia una epistemología del capital intelectual. Recuperdado de http://www.sintesys.cl/assets/capital-intelectual-objeto-o-proceso2.pdf

Ariza, E. D. (2000). Las relaciones de producción y la partida doble. Revista Legis del Contador, 2, 97-132.

Banguero, V. \& Castillo, L. (2009). Aproximaciones en el análisis de las limitaciones al enfrentar la representación contable para la valoración del capital intelectual como activo intangible desde la disciplina contable. Libre Empresa, Universidad Libre seccional Cali, 6(1), 23-42.

Barité-Roqueta, M. G. (2000). Los conceptos y su representación: Una perspectiva terminológica para el tratamiento temático de la información. Scire: Representación y organización del conocimiento, 6(1), 31-53. 
Brooking, A. (1997). El capital intelectual: el principal activo de las empresas del tercer milenio. Barcelona: Ediciones Paidós Ibérica, S.A.

Bueno-Campos, E., Aragón, A., \& García-Morales, V. (2001). El capital intangible frente al capital intelectual de la empresa desde la perspectiva de las capacidades dinámicas. XI Congreso Nacional de ACEDE. Zaragoza, España.

Bueno-Campos, E. (2004). Fundamentos epistemológicos de dirección del conocimiento organizativo: desarrollo, medición y gestión de intangibles. Economía industrial, (357), 13-26.

Burbano, J. E. (1989). Contabilidad: análisis histórico de su objeto y su método. Pliegos Administrativos y Financieros, $12(35)$.

Bustamante-García, H. C. (2013). El interés público en la nueva base institucional de la regulación contable en Colombia. Comentarios generales a propósito del proceso de convergencia hacia estándares contables internacionales. Contaduria Universidad de Antioquia, (56), 81-104.

Cabruja, T., Íñiguez, L., \& Vázquez, F. (2000). Cómo construimos el mundo: relativismo, espacios de relación y narratividad, Anàlisi, 25, 61-94.

Cañibano. L. (1999). Concepto y división de la contabilidad. En Contabilidad: análisis contable de la realidad económica (pp. 41-52). Ediciones Pirámide.

Cañibano, L., Ayuso, M., \& Sánchez, P. (1999). La relevancia de los intangibles para la valoración y la gestión de empresas: revisión de la literatura. Revista Española de Financiación y Contabilidad, 100(Número extraordinario), $17-48$.

Carrizo, W. y León, S. (2011). ¿Qué realidad representa la contabilidad? Pecunia, 5(2007), 17- 27.

Casal, R. \& Viloria, N. (2007). Un breve ensayo sobre el debate entre lo científico y lo técnico en contabilidad. Actualidad Contable FACES, 10(14), 29-36.

Casal, R., Maldonado-Veloza, F., Peña, A., \& Viloria, N. (2010). Problemas epistemológicos de la valoración en contabilidad. Revista Lúmina, (11), 138-145.

Chiavenato, I. (2007). Administración de los recursos humanos (8a ed). México, D. F.: Editorial McGraw-Hill.

Colombia, Congreso de la República (1986). Decreto 2160. Diario Oficial de la República de Colombia, CXXIII, Bogotá, Colombia, 14 de julio de 1986.

Colombia, Congreso de la República (1993). Decreto Reglamentario 2649. Diario Oficial de la República de Colombia, 41156, Bogotá, Colombia, 29 de diciembre de 1993.

Colombia, Congreso de la República (1993). Decreto Reglamentario 2650. Diario Oficial de la República de Colombia, 41156, Bogotá, Colombia, 29 de diciembre de 1993.

Corvellec, H. (2001). La contabilidad por partida doble como forma de representación (Trad. Jorge Capelán). Heterogénesis, (36), 10.

Cuadrado, A. \& Valmayor, L. (1999). Teoría contable. Metodología de la investigación contable. Madrid: McGraw-Hill.

Cubides, H. (1999). Evolución de la capacitación y formación de los Contadores Públicos. En H. Cubides et. al., Historia de la contaduría pública en Colombia siglo XX: Elementos para su interpretación (pp. 35-136). Bogotá: Fundación Universidad Central.

Deleuze, G. \& Guattari, F. (1993). ¿Qué es la filosofía? (T. Kauf, Trad.). Barcelona: Anagrama.

De la Garza-Toledo, E. (1987). Medición, cuantificación y reconstrucción de la realidad. Revista Mexicana de Sociología, 49(1), 281-305.

Diccionario de la Real Academia de la lengua Española (DRAE) (2016). Recuperado de http://dle.rae.es/?id=bJiPo $\mathrm{mE}$

Duarte, T., Arias, R. E. J., \& Tibaná, M. R. (2007). Contabilidad del capital intelectual. Scientia et Technica, 1(35), 339-344.

Drucker, P. (1994). La Sociedad Postcapitalista (J. Cárdenas, Trad.). Bogotá: Norma.

Edvinsson, L. \& Malone, M. (1997). El capital intelectual: Cómo identificar y calcular el valor inexplorado de los recursos intangibles de su empresa (J. Cárdenas, Trad.). Bogotá: Norma. 
Enríquez de Rivera, S. \& Alcalá Canto, M. (Noviembre de 2003). Herramientas para la administración y valuación del capital intelectual. En VIII Congreso Internacional de Costos. Punta del Este, Uruguay.

Fernández, L. L., \& Barbei, A. (2006). La medición en contabilidad: un análisis de sus elementos y limitaciones. Actualidad Contable FACES, 9(12), 75-84.

García-Casella, C. L. (2012). La contabilidad y una fábrica de ladrillos. Contabilidad y auditoría, 12(23), 3-12.

García-Duque, C. (2004). Una discusión crítica sobre el carácter científico de la contabilidad. Revista Lúmina, 5(1), 61-76.

García, M. T., Limone, A., \& Álvarez, C. (1988). El potencial de la empresa y la medición contable. Contaduría Universidad de Antioquia, (12), 73-99. Recuperado de https://aprendeenlinea.udea.edu.co/revistas/index.php /cont/article/view/25017

Geba, N. (2004). Contabilidad como disciplina cientifica, sus especialidades social y financiera. ¿Una ruptura epistemológica? Universidad Nacional de la Plata. Recuperado de https://educacionparaeltrabajoyelser.wikispac es.com/file/view/Contabilidad+como+disciplina+cient\%C3\%ADfica.pdf

Gil, J. M. (2008). La representación de la realidad en los estados contables. Revista D\&G Profesional y Empresaria, Errepar, (104), 534-545.

Gil, J. M. (2010). Retos de la contabilidad frente a la globalización: perspectivas de la teoría y la investigación contable. En C. Barrios y W. Rojas (Comp.), Conjunciones y disertaciones: Pensando la contabilidad en el siglo XXI (pp. 101-126). Cali: Universidad del Valle-Pontificia Universidad Javeriana.

Gómez-Villegas, M. (2010). Dinámica de la concepción y la enseñanza de la teoría contable en Colombia (1970-2000): Una exploración institucional. En C. Barrios y W. Rojas (Comp.), Conjunciones y disertaciones: Pensando la contabilidad en el siglo XXI (pp. 127-159). Cali: Universidad del Valle-Pontificia Universidad Javeriana.

Gómez-Villegas, M. (2011). Pensando los fundamentos de la contabilidad como disciplina académica. Revista Lúmina, (12), 120-150.

Gracia, E. (2009). Problemáticas de la teoría en investigación contable. En C. Barrios y W. Rojas (Comp.), Conjunciones $y$ disertaciones: pensando la contabilidad en el siglo XXI (pp. 43-60). Cali: Universidad del Valle-Pontificia Universidad Javeriana.

Gracia López, É., Ruíz, F., Antonio, R., \& Agudelo Vargas, M. V. (2013). Una crítica de la representación contable en perspectiva histórica: del reflejo de la realidad profunda al "puro simulacro". Revista Cientifica General José María Córdova, 11(12), 79-104.

Green, A. (2006). The transformation of business knowledge into intangible assets. Vine, 36(1), 27-34.

González-Palomo, M. (2003). La evaluación de activos intangibles. Ingenierías, 6(20), 12-17.

González-González, P. (2013). Valoración del activo intangible en empresas mipymes de software. caso de estudio ParqueSoft Cali. Cali: Programa Editorial Univalle.

Hendriksen, E. (1974). Teoría de la contabilidad (M. Fernández, Trad.). México: Unión Tipográfica Editorial HispanoAmericana.

Hincapié, J. P. (2011). Análisis crítico sobre la valoración de los activos intangibles bajo normas nacionales e internacionales. En M. Murgueitio (Comp.), El estudiante como sujeto investigador de su realidad: otras voces: intercambio de saberes y experiencias de los semilleros de investigación en la Facultad de Ciencias Económicas (pp. 45-58). Cali: Editorial Bonaventuriana.

Hincapié, J. P. \& Rincón, L. M. (2016). [Influencias del criterio de razonabilidad en la representación contable y en la toma racional de decisiones]. Trabajo inédito.

IFRS Fundación (2014). Norma Internacional de Contabilidad 38 (NIC 38). Normas Internacionales de Información Financiera, Libro Rojo, 1249-1277. Emitidas el 1 de enero de 2014.

IFRS Fundación (2015). Marco conceptual para la información financiera. Emitido en septiembre de 2010. Recuperado de https://www.mef.gob.pe/contenidos/conta_publ/con_nor_co/no_oficializ/ES_GVT_RedBV2016_conce ptual.pdf 
Kaplan, R., Norton, D., \& Ganzinelli, C. (2006). Mapas estratégicos: convirtiendo los activos intangibles en resultados tangibles. España: Gestión.

Kaufmann, L. y Schneider, Y. (2004). Intangibles: a synthesis of current research. Journal of Intellectual Capital, 5(3), 366-388.

Keller, R. (2011). The sociology of knowledge approach to discourse (SKAD). Human Studies, 34(1), 43-65.

Kristandl, G. \& Bontis, N. (2007). Constructing a definition for intangibles using the resource based view of the firm. Management decision, 45(9), 1510-1524.

Lagrost, C., Martin, D., Dubois, C., \& Quazzotti, S. (2010). Intellectual property valuation: how to approach the selection of an appropriate valuation method. Journal of Intellectual Capital, 11(4), 481-503.

Larrán, J. M. \& Sotomayor, S. (2005). Contabilidad financiera. Valoración y reconocimiento de activos intangibles. Revista internacional LEGIS de Contabilidad y Auditoría, 21(Enero-Marzo), 83-128.

Larrinaga, C. (1999). Perspectivas alternativas de investigación en contabilidad: una revisión. Revista de Contabilidad, 2(3), 103-131.

Lev, B. (2003). Remarks on the measurement valuation, and reporting of intangible assets. Economic Policy Review, (September), 17-22.

Loaiza-Robles, F. (2005). Signo y razón. Exploración semiótica de la partida doble. Revista Lúmina, (6), 55-72.

Loaiza-Robles, F. (2007). El papel de la partida doble en la representación contable. Revista Lúmina, (8), 8-23.

Lópes de Sá, A. (2009). Activos intangibles y la realidad objetiva. Revista internacional LEGIS de Contabilidad y Auditoría, 40(Octubre-Diciembre), 139-159.

Machado, M. A. (2004). Modelos contables y realidad. Una aproximación conceptual a su relación. Revista Lúmina, (5), 93-112.

Machado, M. A. (2009). Una relación crítica bajo el enfoque de la representación. Actualidad Contable FACES, 12(19), $38-55$.

Machado, M. A. (2011). Representación contable: de la revelación de los hechos a la construcción de la realidad. Revista Lúmina, (12), 152-171.

Maldonado-Veloza, F. E. (2011). Crisis de la Práctica Contable vs. Crisis Epistemológica de la Contabilidad. Recuperado de https://papers.ssrn.com/sol3/papers.cfm?abstract_id=1985158

Mantilla-Blanco, S. A. (2004). Capital intelectual, contabilidad del conocimiento. Bogotá: ECOE Ediciones Asociación Colombina de Costos y Contabilidad Directiva.

Mardones, J. M. (1991). Filosofía de las ciencias humanas y sociales: Materiales para una fundamentación cientifica. Barcelona: Anthropos.

Marr, B., Gray, D., \& Neely, A. (2003). Why do firms measure their intellectual capital? Journal of intellectual capital, 4(4), 441-464.

Martínez-Pino, G. L. (2005). Los vaivenes teórico-epistemológicos de la disciplina contable. Revista Lúmina, (5), 33-59.

Martínez-Pino, G. L. (2007). Los paradigmas contables: la borrosa impronta de una interpretación epistemológica. Revista Lumina, (8), 205-234.

Mattessich, R. (2006). La representación contable y el modelo de capas-cebolla de la realidad: una comparación con las "ordenes de simulacro" de Baudrillard y su hiperrealidad. Documento del CIECE. Buenos Aires: Universidad de Buenos Aires.

Mejía-Soto, E., Montes-Salazar, C., \& Montilla-Galvis, O. (2006). Comparación del tratamiento contable de activos intangibles según diferentes organismos reguladores. Los casos de: Colombia, Canadá, chile, México, Estados Unidos, España y el Reino Unido. Universidad ICESI. Estudios gerenciales, 29(99), 89-104.

Nava, D., Ramírez, G., Méndez, A., \& Sánchez, J. (2007). Epistemología de la contabilidad. Revista Icea, 3(5), 104-118. Nevado, D. \& López, V. R. (2002). El capital intelectual: valoración y medición. España: Editorial Prentice Hall.

Nonaka, I. (1994). A Dynamic Theory of Organizational Knowledge Creation. Organization Science, 5(1), 14-37. 
Ochoa, M., Prieto, M. y Santidrián, A. (2007). Estado de la gestión del capital intelectual: evidencia empírica e ideas para la reflexión. Documento de Trabajo. Mayo. Burgos: Universidad de Burgos.

Ospina-Zapata, C. M. (2006). Las tramas de la contabilidad: trazos para quienes empiezan su formación en contaduría pública. Contaduria Universidad de Antioquia, (48), 155-186.

Peña, D. N. y Ruiz, V. R. L. (2002). El capital intelectual: valoración y medición: modelos, informes, desarrollos y aplicaciones. España: Pearson Educación.

Quijano-Valencia, O. (2002). Nuevos tiempos, nuevas competencias. De las mono-competencias a la policognición. En O. Quijano, E. Gracia, G. L. Martínez, E. Ariza y W. Rojas (Eds.), Del hacer al saber. Realidades y perspectivas de la educación cantable en Colombia (pp. 25-83). Popayán: Universidad del Cauca.

Quijano-Valencia, O. (2005). Sociedad y gestión del conocimiento: Los eufemismos del capitalismo cognitivo. Porik An, (10), 205-228.

Quinche-Martín, F. L. (2011). Perspectivas de investigación, retórica y contabilidad: una invitación. Revista Lúmina, (12), 216-239.

Quinche-Martín, F. L. (2012). El potencial de los estudios retóricos en la investigación contable. Revista Facultad de Ciencias Económicas: Investigación y Reflexión, 20(1) 247-268.

Ramírez-Ospina, D. (2007). Capital intelectual: algunas reflexiones sobre su importancia en las organizaciones. Pensamiento y gestión, 23, 1657-6276.

Reilly, R. (1996). The valuation intangible assets. The National Public Accountant, 41(7), 26- 27.

Reilly, R. F. y Schweihs, R. P. (1998). Valuing intangible assets. Boston: McGraw Hill Professional.

Reilly, R. F. (2011). Defining the intangible asset valuation assignment. Journal of Property Tax Assessment \& Administration, 8(4), 45.

Rivero, D., Abad, A., \& Gutiérrez, A. (Octubre 22 de 2008). Capital intelectual. Origen, evolución y desarrollo. Matanzas: Fundación de la Universidad de Matanzas Camilo Cienfuegos.

Rodríguez-Ruiz, O. (2003). Indicadores de capital intelectual: concepto y elaboración. I Congreso Internacional y Virtual de Intangibles. Instituto Universitario de Administración de Empresas. Universidad Autónoma de Madrid, Madrid, España.

Rojas, W. (1996). Consideraciones sobre los alcances de la enseñanza contable. Cuadernos de Administración, 15(23), 173-182.

Rojas, W. (2009). Congoja por una educación contable fútil. Contaduria Universidad de Antioquia, (52), 259-274.

Roos, J., Roos G., Dragonetti, N., \& Edvinsson, L. (1997). Capital intelectual: el valor intangible de la empresa. Barcelona: Ediciones Paidós Ibérica.

Scheutz, M. (1999). The Ontological Status of Representations. En A. Riegler, M. Perschl y A. von Stein (Edits.), Understanding representation in the cognitive sciences (pp. 33-38). U.S.: Springer.

Sierra-González, E. M. (2001). Evolución de la normativa contable en Colombia. Innovar: Revista de ciencias administrativas y sociales, (17), 47-65.

Sierra-Molina, G. \& Moreno-Campos, I. (2000). La información contable sobre el capital humano: opinión de analistas financieros. Revista partida doble, 116, 60-71.

Simó, P. \& Sallán, J. M. (2008). Intangible capital and intellectual capital: literature review. Definitions and Agenda for Research, 26(2), 65-78.

Stewart, T. (1997). La nueva riqueza de las organizaciones: el capital intelectual. Buenos Aires: Ediciones Granica S.A. Talha, M. (2004). Valuation of intangible assets in accounting. Construction, Accounting \& Taxation, 14(1), 25-31.

Tascón-Fernández, M. T. (1997). La contabilidad como disciplina científica. Contaduría y Administración, (187), 69-94.

Tissen, R., Andriessen, D., \& Deprez, F. L. (2000). El valor del conocimiento: para aumentar el rendimiento en las empresas (E. Paz, Trad.). Madrid: Prentice Hall-Pearson. 
Tua-Pereda, J. (1995). Lectura de teoría e investigación contable: la evolución del concepto de contabilidad a través de sus definiciones. Medellín: División Editorial CIJUF.

Vargas-Montoya, P. (2000). Caracteristicas de los activos intangibles. La Rioja: Universidad de La Rioja.

Viloria, N. (2001). Epistemología de las Ciencias Contables. Actualidad Contable FACES, 4(4), 63-71.

Viloria-Martínez, G., Nevado Peña, D., \& López Ruiz, V. (2008). Medición y valoración del capital intelectual. Fundación EOI.

Vlaemminck, J. (1961). Historia y doctrinas de la contabilidad (J. M. González, Trad.). Madrid: Editorial Index.

Whitley, R. D. (2011). Posibilidad y utilidad de la teoría positiva de la contabilidad. Cuadernos de Administración, 12(17), 18-37.

Zambon, S. (2016). Ten years after: the past, the present and the future of scholarly investigation on intangibles and intellectual capital (IC). Journal of Intellectual Capital, 17(1).

Zéghal, D. \& Maaloul, A. (2011). The accounting treatment of intangibles - A critical review of the literature. Accounting Forum, 35(4), 262-274.

\section{Anexo 1}

Mapa conceptual. Semejanzas y diferencias entre las definiciones del concepto de intangibles en la literatura contable y administrativa

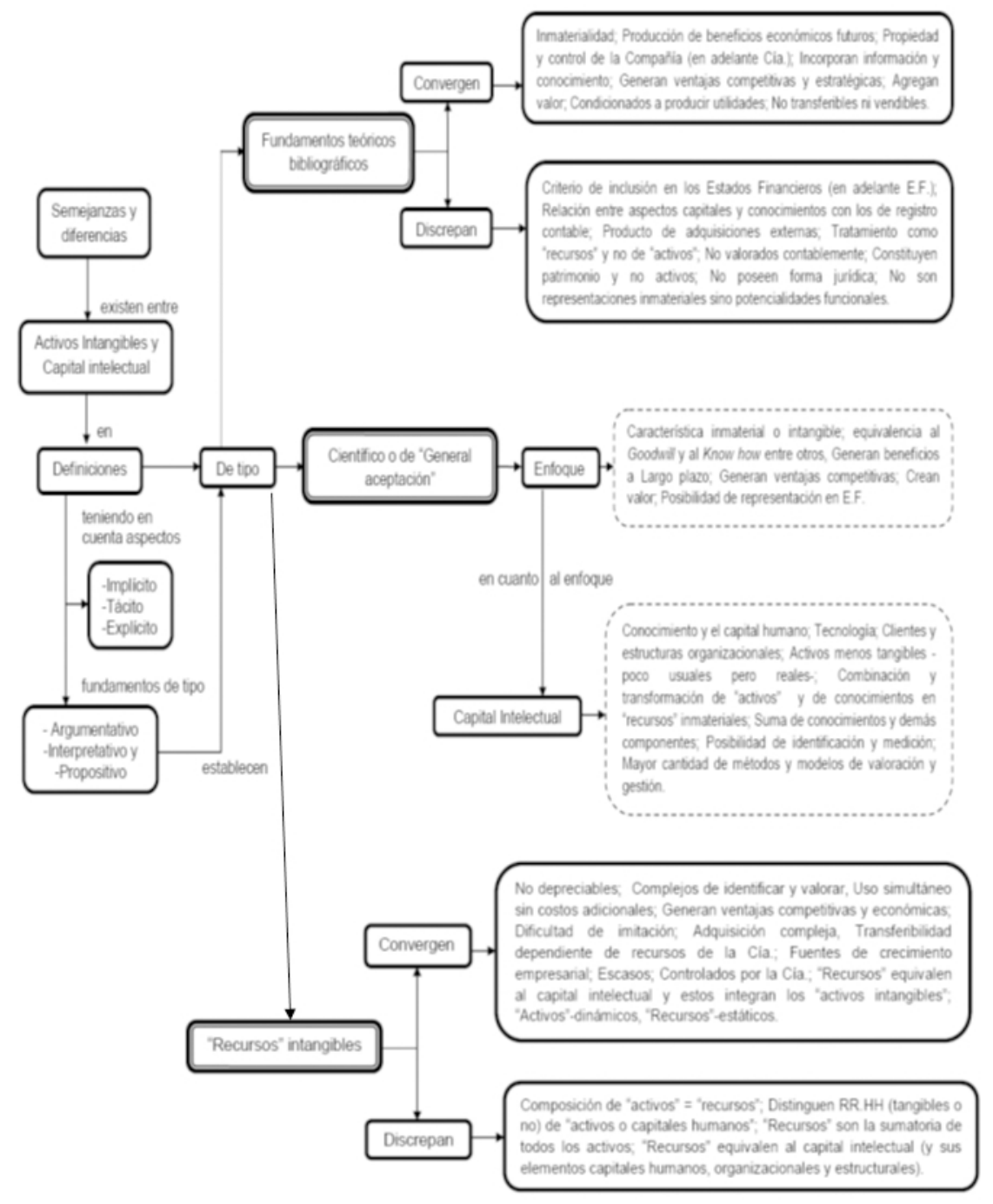

Fuente: elaboración propia 


\section{Notas}

* Artículo de investigación

1 La revisión de la literatura, incluida o no en este documento, sugiere la observancia de un interflujo de discursos que tienen epicentro en el plano profesional y disciplinal contable, de manera que debiésemos referirnos a múltiples discursos, y no a uno solo.

2 Que puede o no tener, o más específicamente, producir sentido. Asimismo, cabe observar que los informes contables deben ser considerados como dispositivos retóricos que pueden manipular la percepción de los usuarios contables.

3 Para ampliar la discusión sobre medición y valoración contable, sugerimos ver la conferencia del profesor Gómez-Villegas titulada Medición y valoración contable: una aproximación heterodoxa, presentada en el marco de las Primeras jornadas de investigación en contabilidad crítica realizadas el día 19 de abril de 2016 en la Universidad Nacional de Colombia.

$4 \quad$ Traducciones del inglés del autor.

5 Reilly (1996); Reilly y Schweihs (1998); Cañibano, Ayuso y Sánchez. (1999); Bueno-Campos, Aragón y García-Morales (2001); Lev (2003); Marr, Gray y Neely (2003); González-Palomo (2003); Talha (2004); Bueno-Campos (2004); Kaufmann y Schneider (2004); Green (2006); Andreou, Green y Stankosky (2007); Kristandl y Bontis (2007); Simó y Sallán (2008); Lagrost, Martin, Dubois y Quazzotti (2010); Zéghal y Maaloul (2011); Hincapié (2011); Zambon (2016).

6 El mapa conceptual se elaboró a partir de Nonaka (1994); Brooking (1997); Edvinsson y Malone (1997); OchoaMartínez, Prieto y Santidrián (2007); Vargas-Montoya (2000); Sierra-Molina y Moreno-Campos (2000); BuenoCampos (2004); Nevado y López (2002); Rodríguez (2003); Mantilla-Blanco (2004); Larrán y Sotomayor (2005); Mejía-Soto, Montes-Salazar y Montilla-Galvis (2006); Kaplan, Norton y Ganzinelli (2006); Duarte, Arias y Tibaná (2007); Viloria-Martínez, Nevado Peña y López Ruiz (2008); Lópes de Sá (2009); Stewart (1997); Roos, Roos, Dragonetti y Edvinsson (1997); Alama Salazar, De Castro y López Sáez (2006); Chiavenato (2007); Rivero, Abad y Gutiérrez (2008).

7 Un aporte en esta dirección puede encontrarse en "Análisis crítico del contenido discursivo: una aproximación hermenéutica al concepto de activos intangibles desde su perspectiva normativa”, trabajo inédito del mismo autor de este artículo (Hincapié \& Rincón [2016]), que está en proceso de revisión para su publicación en la revista Cuadernos de Contabilidad de la Pontificia Universidad Javeriana. Anexo 1

\section{Licencia Creative Commons CC BY 4.0}

Para citar este artículo: Hincapié, J. P. (2017). Elementos ontológicos, epistemológicos y metodológicos para la construcción de un marco teórico de estudio de los activos intangibles. Cuadernos de Contabilidad, 18(45), 86-109. https://doi.org/10.11144/Javeriana.cc18-45.eoem 